Article

\title{
Finite Element Simulations of Hard-On-Soft Hip Joint Prosthesis Accounting for Dynamic Loads Calculated from a Musculoskeletal Model during Walking
}

\author{
Alessandro Ruggiero ${ }^{1, *(D)}$, Massimiliano Merola 2 (D) and Saverio Affatato $^{2}(\mathbb{D})$ \\ 1 Department of Industrial Engineering, University of Salerno, Via Giovanni Paolo II, nr. 132, \\ 84084 Fisciano, Italy \\ 2 Medical Technology Laboratory, IRCCS—Rizzoli Orthopaedic Institute, Via di Barbiano, 1/10, \\ 40136 Bologna, Italy; massimiliano.merola@ior.it (M.M.); affatato@tecno.ior.it (S.A.) \\ * Correspondence: ruggiero@unisa.it; Tel.: +39-089-964-312
}

Received: 20 March 2018; Accepted: 5 April 2018; Published: 9 April 2018

\begin{abstract}
The hip joint replacement is one of the most successful orthopedic surgical procedures although it involves challenges to overcome. The patient group undergoing total hip arthroplasty now includes younger and more active patients who require a broad range of motion and a longer service lifetime for the replacement joint. It is well known that wear tests have a long duration and they are very expensive, thus studying the effects of geometry, loading, or alignment perturbations may be performed by Finite Element Analysis. The aim of the study was to evaluate total deformation and stress intensity on ultra-high molecular weight polyethylene liner coupled with hard material head during one step. Moving toward in-silico wear assessment of implants, in the presented simulations we used a musculoskeletal multibody model of a human body giving the loading and relative kinematic of the investigated tribo-system during the gait. The analysis compared two frictional conditions -dry and wet and two geometrical cases- with and without radial clearance. The loads and rotations followed the variability of the gait cycle as well as stress/strain acting in the UHWMPE cup. The obtained results allowed collection of the complete stress/strain description of the polyethylene cup during the gait and calculation of the maximum contact pressure on the lateral edge of the insert. The tensional state resulted in being more influenced by the geometrical conditions in terms of radial clearance than by the variation of the friction coefficients due to lubrication phenomena.
\end{abstract}

Keywords: total hip arthroplasty; musculoskeletal multibody model; dynamic loading; finite element analysis; radial clearance; dry and wet friction

\section{Introduction}

Total Hip Replacement (THR) is the most successful application of biomaterials in the short term in order to alleviate pain, restore joints, and increase functional mobility in diseased traumatized articulations [1-3]. A major limiting factor to the service life of THRs remains the wear of the polyethylene acetabular cup [4,5]. Preclinical endurance testing has become a standard procedure to predict the mechanical performance of new devices during their development. Wear tests are performed on different materials and designs used in prosthetic implants $[1,6-8]$ to obtain quality assessment and acquire further knowledge about the tribological processes of joint prostheses. The objective of these investigations is to find out the wear rate and its dependence on the test conditions. In order to obtain realistic results, a wear test should reproduce the in vivo working conditions on the artificial implants [9].

It is well known that wear tests that are close to the in vivo conditions have a long duration and elevate costs $[1,10,11]$. The wear simulation is run for several million cycles, considering that 
one million cycles corresponds to one year in vivo [12-14]. The running-in period encompasses approximately the first half a million cycles; the steady-state wear is assessed by measuring the wear after the running-in period [15]. Wear is evaluated either gravimetrically, determining the weight loss of the components, or by measuring the volume of the material that has been removed, e.g., wear pit dimensions $[9,16]$. Lubricant absorption or creep of the loaded components, especially for polyethylene, is considered. Wear measurements are normally done at lubricant change stops, e.g., every 500,000 cycles.

Finite Element Analysis (FEA) has been widely used in many areas of biomechanics and medical engineering [17]. The numerical modelling tool of finite element analysis has been widely applied to study the behavior of articular cartilage, joints, and bone structures under compressive and tensile stresses. Structural applications include the design and development of joint prosthesis and fracture fixation devices. FEA enables to investigate parameters and boundary conditions, which are not accessible experimentally nor analytically. It has been applied to orthopedic devices to gain a deep understanding of the behavior of the bone-implant system and to support the design and pre-clinical testing of new devices. Thus, computational wear simulation can be a valuable complement to wear tests, e.g., in predictions of the lifetime of prostheses evaluating the effects of geometry, loading, or alignment perturbations.

As the first attempt to apply FEA to the orthopedic field dates back to 1972 [18], there have been four decades of developing and improving this methodology, along with the increase of computational power. Nevertheless, to make in silico wear simulation meaningful, better wear models are needed through advanced study design and corroboration with in vitro testing. The most intricate aspect of such models is the loading conditions acting on the implants, as their knowledge is still not fully reached. Few hip replacements have been subjected to direct load measures from Bergmann et al. [19-21], which limits the result validity to the subjects of the study. A more general load analysis can be obtained by muscular skeletal models, as it has been done by the authors [22], to study knee implants, or by van der Ploeg et al. [23], who used the multibody results as input for a FEA studying the micro-motions of a femoral stem.

In this work, a musculoskeletal multibody model was used in order to estimate the loads acting on the hip joint during walking. A finite elements analysis was then conducted using these loads and kinematic inputs. The study reports the results in terms of total deformation and stress intensity of an acetabular polyethylene liner coupled with a femoral head of a hard (ideally rigid) material.

\section{Materials and Methods}

\subsection{Gait Cycles and Loads}

In this study, the authors used a musculoskeletal modelling software to estimate loads acting on the hip joint during level walking. The simulation was performed with AnyBody Modelling System ${ }^{\mathrm{TM}}$ (AMS) [24]. To calculate the joint forces, knowledge of kinematic data and ground reaction forces that are used as input is required. These data are collected in gait analysis laboratories using special motion capture tools [25], which allows the measurement of a subject's gait through cameras that monitor markers on the subject's skin.

In inverse dynamics, the motion and the external loads on the body are known, and the aim is determining the internal forces. However, not enough equilibrium equations are available to find all the unknowns of the problem, therefore the calculation of the muscle forces is possible by the so-called redundancy problem. The solution of the muscle recruitment problem in the inverse dynamics approach is generally formulated as an optimization problem of the form:

$$
\min G\left(f^{(M)}\right)
$$

with

$$
C f=d
$$




$$
0 \leq f_{i}^{(M)} \leq N_{i}, i \in\left\{1, \ldots, n^{(M)}\right\},
$$

where $G$ is the objective function (1), i.e., the assumed criterion of the recruitment strategy of the central nervous system, stated in terms of the muscle forces, and minimized with respect to all unknown forces in the problem, $f=\left(f^{(M) T} f^{(R) T}\right)^{T}$, (i.e., muscle forces and joint reactions). Equation (2) is the dynamic equilibrium equations, which enter as constraints into the optimization. $C$ is the coefficient matrix for the unknown forces/moments in the system, $d$ is a vector of the known applied loads and inertia forces. The non-negativity constraints on the muscle forces, Equation (3), states that muscle can only pull, not push and the upper bounds limit their capability, so $N_{1}$ is the strength of the muscle.

The most popular forms of the objective function $G$, calculated from the relative intensity and normalized for each muscle, are the polynomial criteria and the soft saturation criteria per Siemienski et al. [26]:

$$
G\left(f^{(M)}\right)=\sum_{i=1}^{n^{(M)}}\left(\frac{f_{i}^{(M)}}{N_{i}}\right)^{p}
$$

with $p=2$, since it is established in the literature as predicting reasonable muscle activation patterns for the type of analyzed trial.

All segments of the biomechanical system are modelled as rigid bodies, neglecting effects such as the wobbly masses of soft tissues.

\subsection{Finite Element Modelling}

The finite elements model was realized through Ansys ${ }^{\circledR}$ Workbench commercial software (v.18.1, ANSYS Inc., Canonsburg, PA, USA). To minimize the computational complexity there were considered only the two major bearing components in a hip implant, namely the femoral head and the acetabular cup. The presence of the pelvic bone has been neglected, since its influence has a least effect on contact pressure [27]. The bodies of the FE model are shown in Figure 1, the mesh was realized through quadratic tetrahedral elements. Mesh convergence tests were performed, resulting in a total number of elements and nodes of 2012 and 3283, respectively, having 383 contact elements.

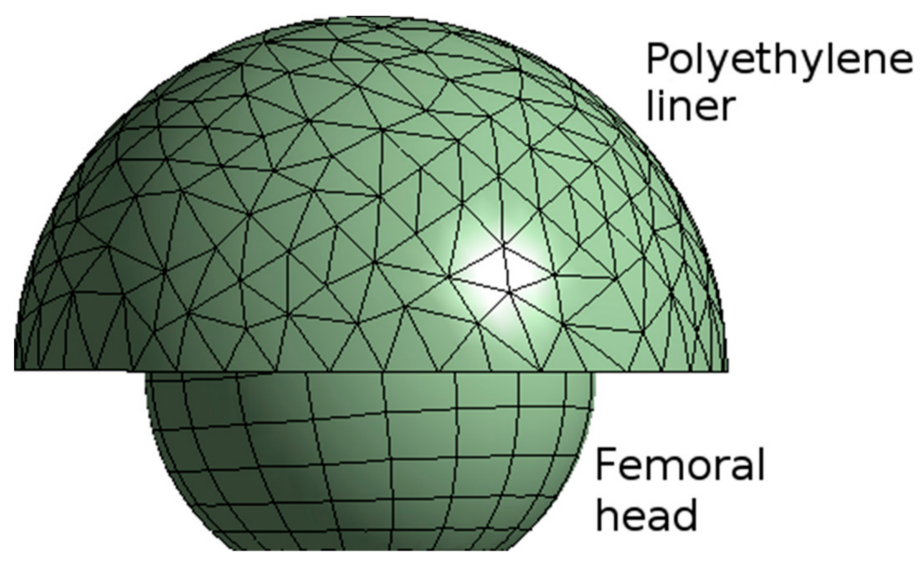

Figure 1. Mesh model of the femoral head and the polyethylene liner.

To solve the contact problem the Augmented Lagrange algorithm was used, considering an asymmetric behavior, which is recommended for the solution of frictional contacts. The femoral head was modelled as a rigid body, whereas for the polyethylene insert of the cup it was selected the Ultra-High-Molecular-Weight-Polyethylene (UHMWPE) GUR 1050 material, as it is one of the main polymer materials used for implant applications [28,29]; Table 1 summarizes its main parameters. 
Table 1. UHMWPE GUR 1050 attributes.

\begin{tabular}{ccccccc}
\hline $\begin{array}{c}\text { Density } \\
\mathbf{( k g} \cdot \mathbf{m}^{-\mathbf{3}} \mathbf{)}\end{array}$ & $\begin{array}{c}\text { Young's } \\
\text { Modulus } \\
\mathbf{( M P a )}\end{array}$ & $\begin{array}{c}\text { Poisson's } \\
\text { Ratio } \\
\mathbf{( - )}\end{array}$ & $\begin{array}{c}\text { Bulk } \\
\text { Modulus } \\
\mathbf{( M P a )}\end{array}$ & $\begin{array}{c}\text { Shear } \\
\text { Modulus } \\
\mathbf{( M P a )}\end{array}$ & $\begin{array}{c}\text { Tensile Yield } \\
\text { Strength } \\
\mathbf{( M P a )}\end{array}$ & $\begin{array}{c}\text { Tensile } \\
\text { Ultimate Strength } \\
\mathbf{( M P a )}\end{array}$ \\
\hline 930 & 690 & 0.43 & 1640 & 241 & 21 & 40 \\
\hline
\end{tabular}

The material is assumed to be homogenous and isotropic. Even if roughness plays a key role on the tribological behavior of hip implants [30,31], the model surfaces are considered smooth, as in most of the models found in literature, for the ease of solution.

The study was conducted to understand the stress behaviour in dry conditions, as the presence of lubricant modifies the pressure distribution on the surfaces. However, as further knowledge, the influence of the friction coefficient was introudced, comparing a dry and a lubricated regime, namely, a DRY case, i.e., no lubrication, and a WET case, i.e., lubricated conditions. The mean values of the friction coefficient in lubricated conditions were extracted from experimental studies on the prosthesis tribological pairs [32,33]. Thus, a dry friction value of 0.13 and a mean wet friction value of 0.05 was selected.

The femoral head had a diameter of $28 \mathrm{~mm}$, whereas the acetabular cup had a thickness of $5 \mathrm{~mm}$. Moreover, two geometrical configurations of the coupled bodies were studied, and the simulations were executed considering the presence of the radial clearance (CC condition) and not considering it (NC condition). Radial clearance is the difference between the radius of the acetabular cup and the one of the femoral head (see Figure 2). Radial clearance, when considered, was $0.5 \mathrm{~mm}$ [34]; the results of the two configurations were then compared.

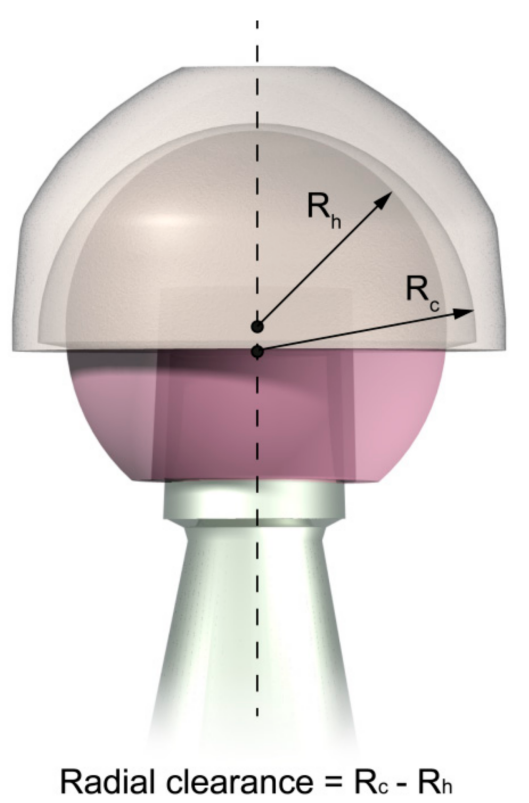

Figure 2. Radial clearance is the difference in radius of the acetabular cup and the femoral head. In this image the clearance is amplified for a better understanding.

The input data obtained by the multibody system were evaluated in a local coordinates system, which follows the movements of the femoral head. As the FE model requires a global coordinates system, a conversion was performed considering well-known geometric transformations [35]. Further force components and mesh orientations are defined with respect to a pelvic reference frame that coincides with the true anatomic superior, anterior, and lateral directions (see Figure 3). The tensional state and the total deformation were evaluated on the inner surface of the polyethylene liner. 


\section{Results}

The forces and the rotations taking place along the three degrees of freedom were gained from the multibody analysis. The force components are the ones depicted in Figure 3 . The three rotations around the axes are the Flexion/Extension (around $z$ axes), Abduction/Adduction (around $x$ axes) and Inward/Outward (around $y$ axes).

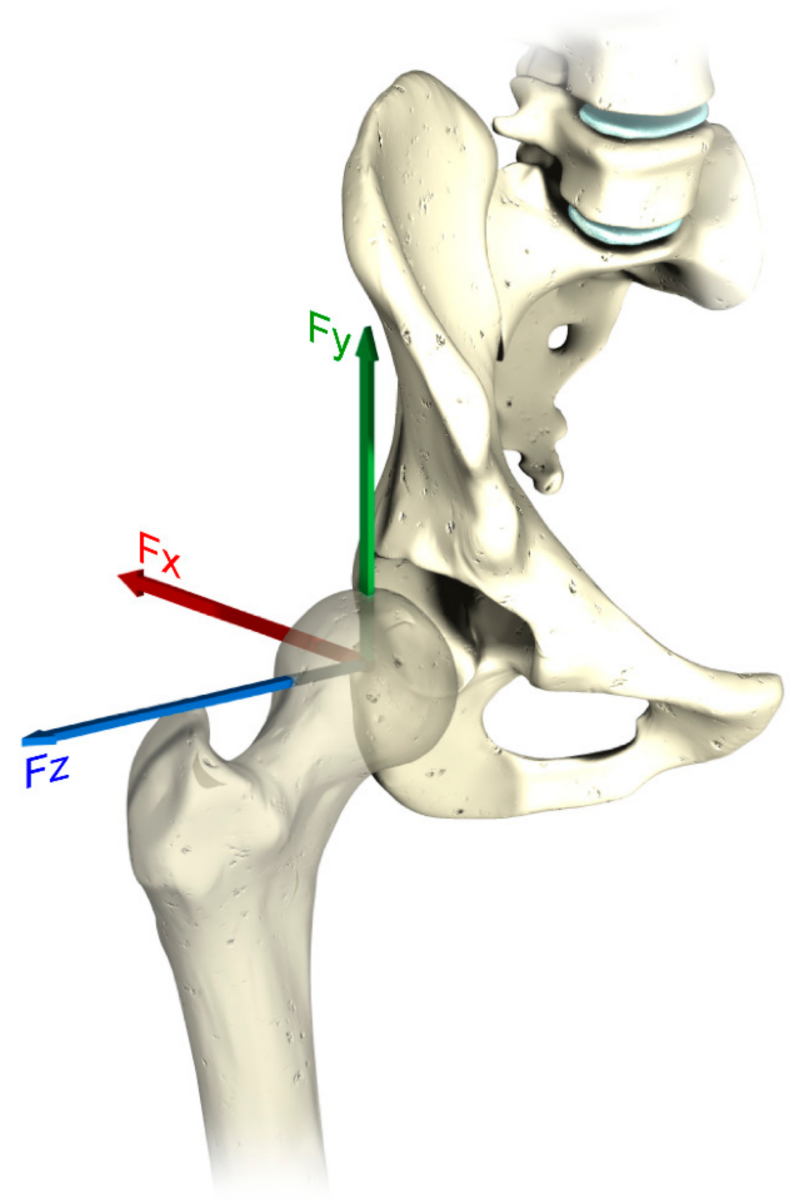

Figure 3. The three force vectors represented on a femoral head.

In Figure 4 the force components and the rotations derived from the model are shown. It is noticeable that the highest rotation is the Flexion/Extension, whereas the highest load is along the $y$ axes. Forces and rotations so obtained were used as dynamic inputs for the finite element model.

In Figure 5 the pressure distribution on the internal surface of the cup in different instants of the cycle is shown, with regards to the dry NC condition as exemplificative case. Along with the different orientation of the femoral head it is possible to observe the pressure distribution on the polyethylene liner. Its highest values are found at $8 \%$ and $48 \%$ of the cycle (respectively Figure $5 \mathrm{a}, \mathrm{c}$ ). In the latter case the highest level of the Anterior / Posterior force was also found (see Figure 4), and the pressure is more concentrated in the edge zone of the insert. In the other two images, Figure $5 \mathrm{~b}, \mathrm{~d}$, at $26 \%$ and $93 \%$ of the cycle, the pressure reaches lower values and its mostly located in the central part of the inner hemisphere. The other geometrical and frictional cases are here omitted for brevity, but they presented a similar distribution of pressure, only leading different intensity of the tensional state. 

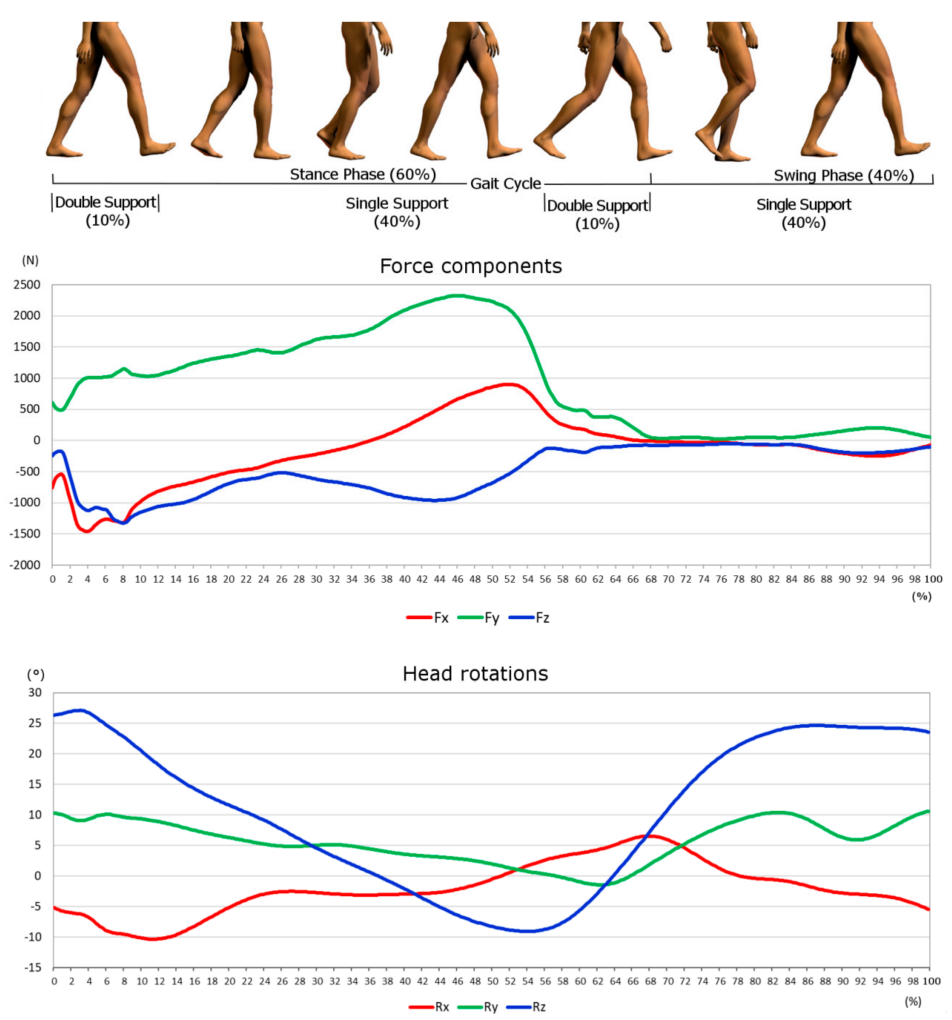

Figure 4. Forces components, in red Fx, in green Fy, in blue Fz. Head rotations, around $x$ axes in red, $y$ axes green and $z$ axes blue.
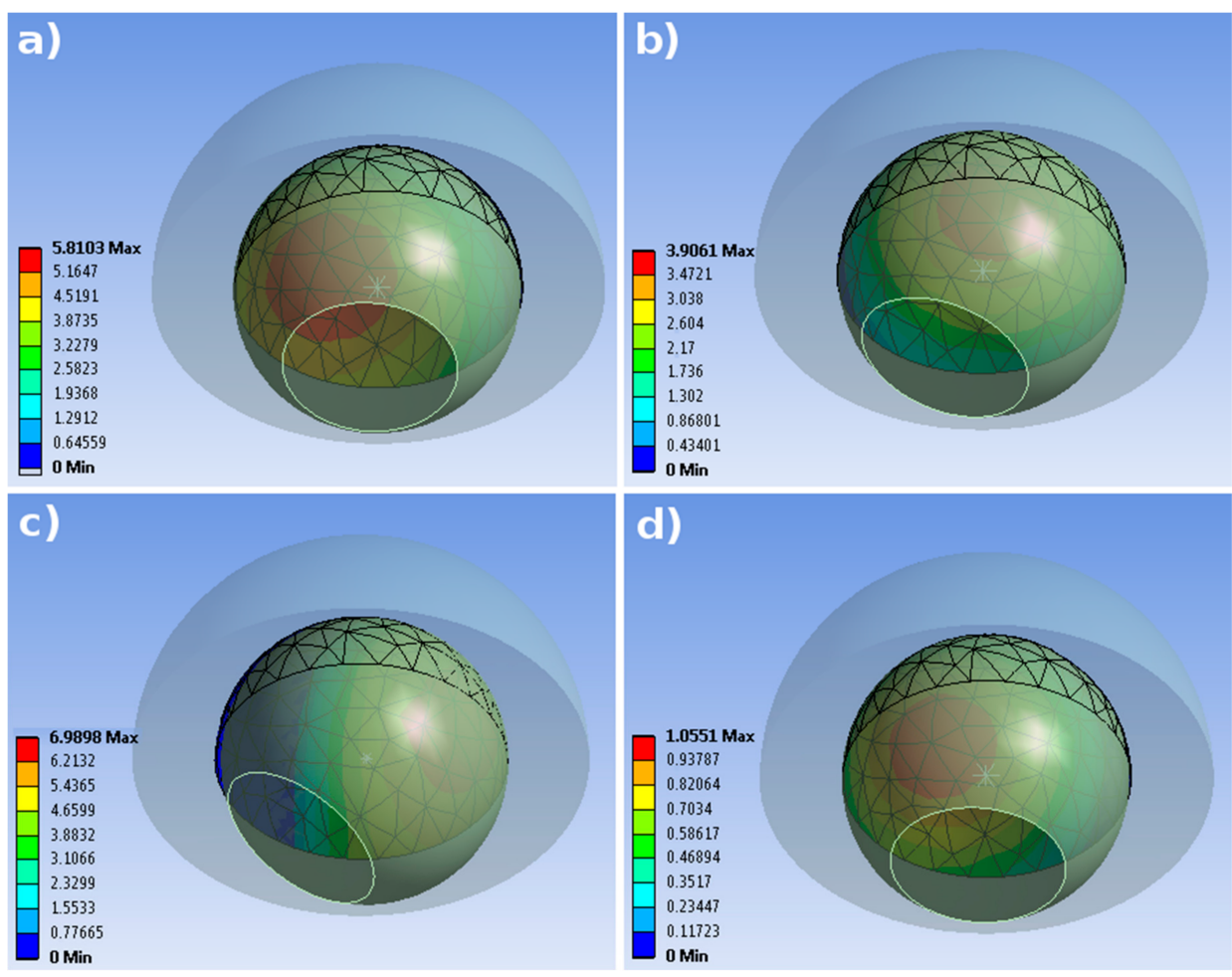

Figure 5. Pressure distribution on the internal surface of the acetabula cup. (a) NC case, dry condition; (b) NC case, wet condition; (c) CC case, dry condition; (d) CC case, wet condition. 
Figures 6 and 7 present a summary of the maximum values of pressure and total deformation, comparing the two friction conditions and the two geometric configurations. In Figure 6a the maximum value of pressure is shown, for each part of the cycle. The maximum value throughout the walking cycle is equal to $7 \mathrm{MPa}$ and it is found around $48 \%$ of the way through the cycle-agreeing with the dynamic analysis. A slight difference was found between the two friction cases, showing a higher peak value in the wet condition. In Figure $6 c$ the maximum value of the total deformation is displayed; its highest value is again related to the wet case, reaching almost $0.6 \mathrm{~mm}$. In Figure $6 \mathrm{~b}, \mathrm{~d}$ the comparisons are shown, in terms of pressure and deformation, between the two friction cases considering the presence of the radial clearance (CC). In Figure $6 \mathrm{~b}$, the comparison highlights the almost complete lack of difference in the two friction conditions; the highest value reached is almost $10 \mathrm{MPa}$. However, in Figure $6 \mathrm{~d}$ the curves have some differences, showing slightly higher values of total deformation in wet condition (maximum value of $1 \mathrm{~mm}$ and $0.9 \mathrm{~mm}$ for the wet and the dry case, respectively).

In Figure 7 the comparison of the two geometrical conditions is presented, with and without radial clearance (CC and NC, respectively). In Figure 7a, considering the boundary lubrication, the maximum pressure plot shows the large divergence in the two geometrical solutions. The highest values are almost $10 \mathrm{MPa}$ and $6.7 \mathrm{MPa}$, for the $\mathrm{CC}$ and $\mathrm{NC}$ respectively. As well as the curves in Figure 7c, where the total deformation is shown, the highest values are found for the $\mathrm{CC}$ condition where it reaches almost $1 \mathrm{~mm}$, whereas NC gives back at the most $0.6 \mathrm{~mm}$. The curves in Figure $7 \mathrm{~b}$ also brings out the divergences in the two geometrical configurations under dry friction, the pressure in CC being higher than the one found in NC; the values are almost the same as those already described in the wet condition. Figure $7 \mathrm{~d}$ reports the maximum values of the total deformation, clearly showing the difference in the CC and NC conditions.

a)

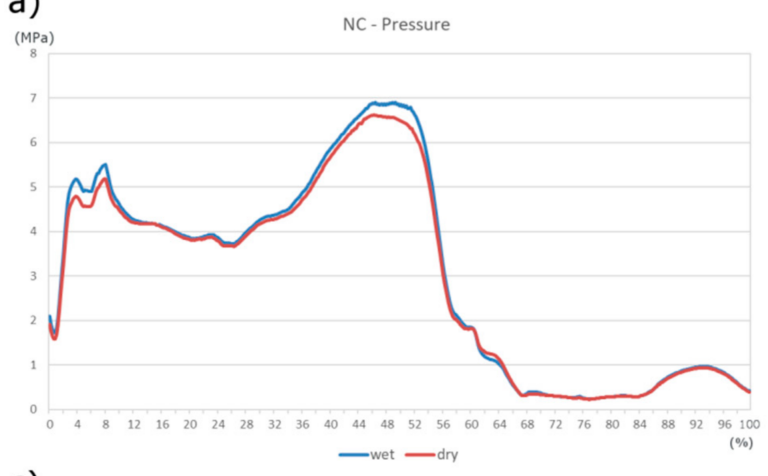

c)

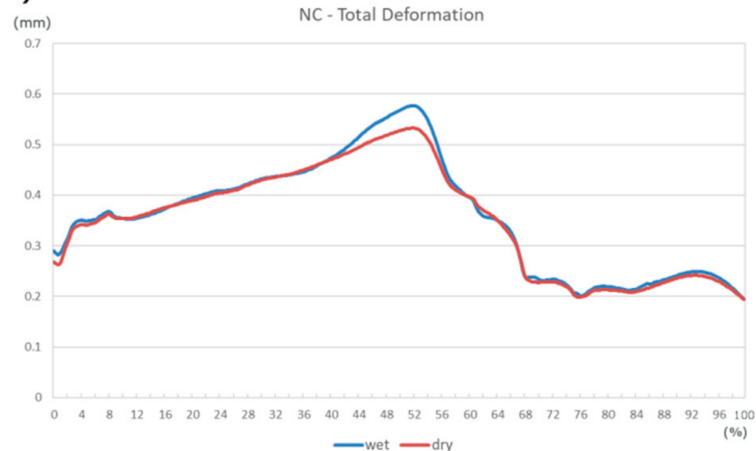

b)

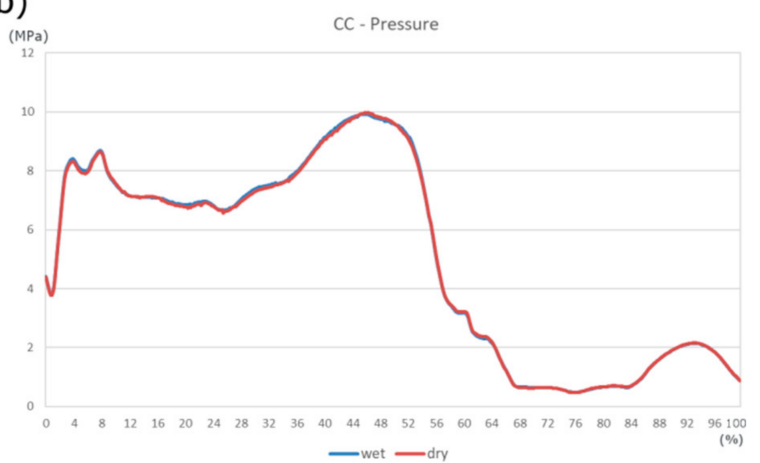

d)

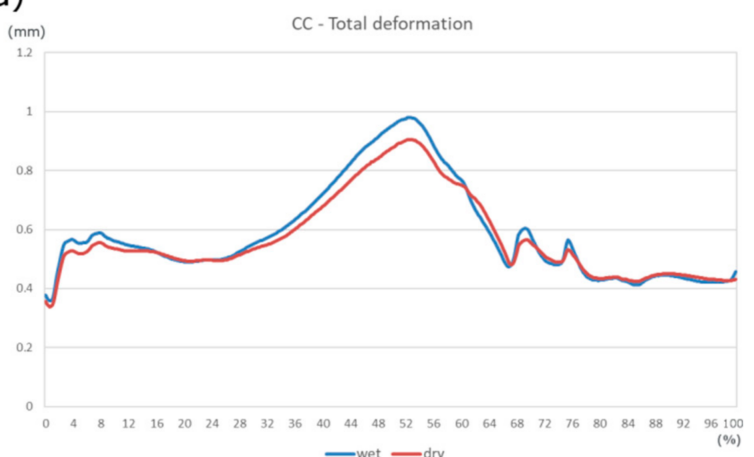

Figure 6. Comparison of result in the NC $(\mathbf{a}, \mathbf{c})$ and $C C(\mathbf{b}, \mathbf{d})$ cases, between the dry and wet conditions. 
a)

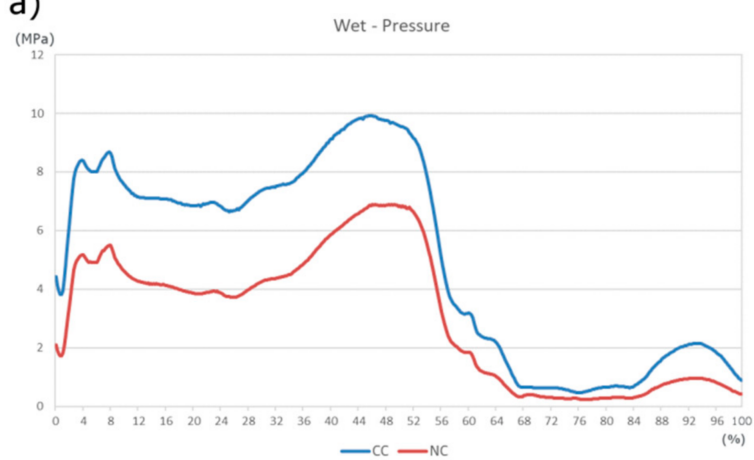

c)

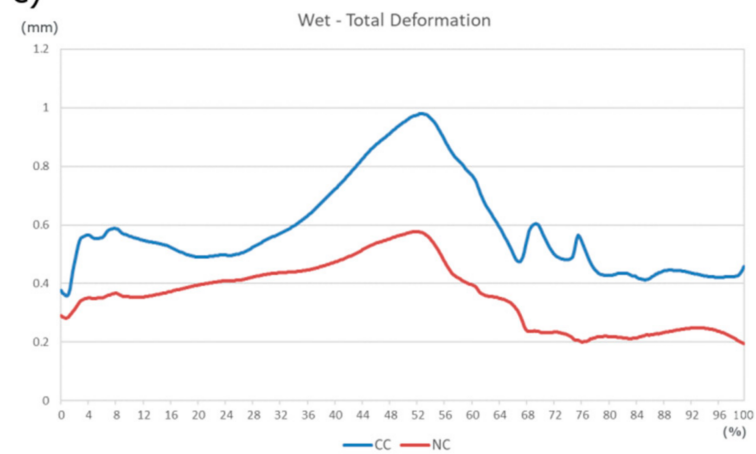

b)

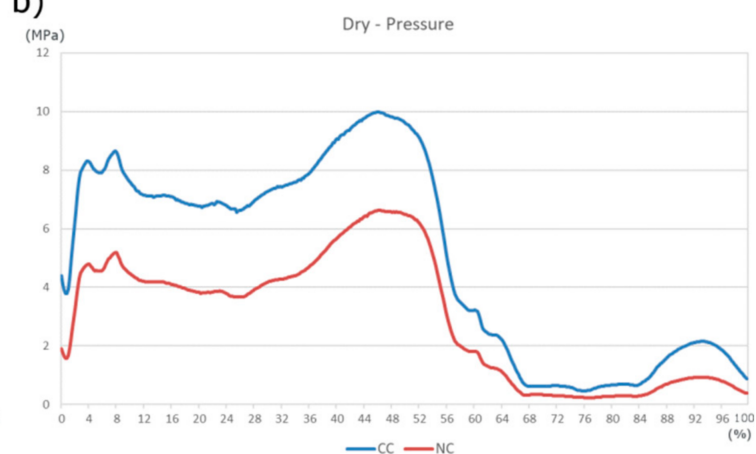

d)

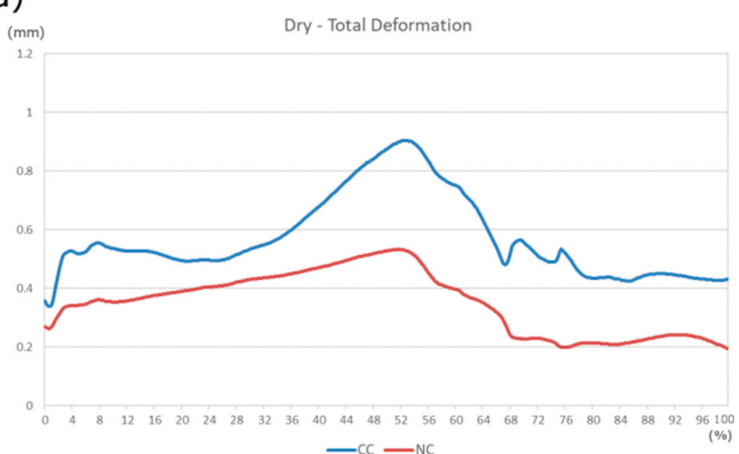

Figure 7. Comparison of result in the wet $(\mathbf{a}, \mathbf{b})$ and dry $(\mathbf{c}, \mathbf{d})$ condition, between the CC and NC cases.

\section{Discussion}

In this work, the forces and rotations acting on the hip joint during a complete gait cycle were first evaluated by solving the inverse dynamic problem. These data agree with the walking cycle variability [25], showing how the joint results more loaded during the stance phase than in the swing phase, when there is almost no contact between the foot and the ground. Furthermore, the highest loads is the axial (along the $y$ axes) as expected and confirmed by a comparison with the standard ISO 14242-1:2012 [36]. Afterwards, these loads and rotation were used as dynamical input in the finite element model, obtaining the pressure distribution and the elastic deformation on each node of the surface during the whole gait cycle. The stress state of the internal surface of the UHMWPE liner reaches peaks of the order of $10 \mathrm{MPa}$, being in accordance with literature results [37-39]. Several authors $[36,40,41]$ used simplified hip kinematic and gait load, such as one-dimensional vertical load or considered only the flexion/extension rotation [40], which does not represent actual physiological loading, plus these studies rely on ISO standards at the expense of a flexible design. In this regard, the original contribution of the study is the acquisition of stress and deformation distribution based on a multibody model. This offers the possibility to apply a wide variety of gaits and to consider the peculiarity of a specific class of patients, e.g., older or younger people. This could lead to the design of prosthesis which account the requirement of a patient, by simply characterize his activity through the multibody and finite elements model.

The comparison of the different working conditions allowed the conclusion that the presence of radial clearance strongly influences the tensional state of the coupled surfaces. Whereas, for a complete understanding of the lubrication influence on the tribology of hip implants the Reynolds equations must be involved [42], as varying the coefficient of friction does not allow the establishment of a sensible difference in results. In literature, the contact is usually assumed to be frictionless, justifying this hypothesis with negligible variation in contact pressure distribution. However, the presence of a frictional force has an influence to the location of the nominal contact point, as demonstrated by Mattei and Di Puccio in [35]. 
The reasons for the differences across the two geometrical conditions are ascribable to the different tensional state of the surfaces. In the geometry without radial clearance a conformal contact is realized, meaning that the contact is distributed along an area. On the other hand, when the radial clearance is considered, the contact become non-conformal, which implies that the contact is limited to a small area that increases its extension as the deformation rises. These differences in the area size led to the distinction of the pressure values, shown in the previous paragraph. As stated by Teoh et al. [37] the radial clearance plays a vital role in the wear process, finding that its extreme values $(0.001$ and $0.5 \mathrm{~mm}$ ) led to the highest level of wear. In the study by Tudor et al. [43] the difference between the conditions of small loads with high clearances is highlighted, where the contact pressure tends to a Hertzian distribution, and high loads with small clearances, where the contact pressure tends to have a hyperbolic distribution. Furthermore, concerning the influence of the frictional force, in the study by Teoh et al. [37] they found that varying the friction coefficient between 0 and 0.3 , only yielded a slightly variance of the wear rate.

\section{Conclusions}

This work is meant as a first step forward to the simplified hip kinematic and gait load. In this work we presented a dynamic load, derived by a multibody technique applied to a musculoskeletal model, considering the variability of the load direction during gait movement.

The main conclusions of the study are:

- multibody technique applied to a musculoskeletal model was proven to be a valid instrument to obtain a flexible design of implant, leading to the evaluation of load for a specific demanding task;

- load components and rotations match the variability between the stance and the swing phase of the leg during the gait;

- highest values of pressure on the inner surface of the polyethylene insert are found near its edge side;

- tensional state and elastic deformation are mainly influenced by the radial clearance rather than the friction coefficient.

The results of the present work offer the possibility to extend, in further studies, the range of kinematics and dynamics; an additional improvement could include lubrication to apply this set-up in a realistic scenario.

Acknowledgments: The authors would like to thank Simone Di Stasio (University of Salerno) for his help with the finite element model. This work was partially supported by the Italian Program of Donation for Research "5 per mille", year 2014, and by FARB 2016 obtained from University of Salerno.

Author Contributions: A.R. and S.A. conceived and designed the investigation; A.R. developed the dynamical analysis; M.M. performed the FEM model; M.M. and S.A. analyzed the data; A.R. and S.A. discussed the results; A.R., M.M. and S.A. wrote the paper.

Conflicts of Interest: The authors declare no conflict of interest.

\section{Nomenclature}

THR

AMS

FEA

UHMWPE

G

$f^{(M)}$

$f^{(R)}$

$d$

$N_{1}$
Total Hip Replacement

AnyBody Modelling System

Finite Element Analysis

Ultra-High-Molecular-Polyethylene

objective function

muscle forces

joint reaction

vector of applied loads and inertia forces

strength of the muscle 


\section{References}

1. Affatato, S.; Freccero, N.; Taddei, P. The biomaterials challenge: A comparison of polyethylene wear using a hip joint simulator. J. Mech. Behav. Biomed. Mater. 2016, 53, 40-48. [CrossRef] [PubMed]

2. Learmonth, I.D.; Young, C.; Rorabeck, C. The operation of the century: Total hip replacement. Lancet 2007, 370, 1508-1519. [CrossRef]

3. Kurtz, S.; Ong, K.; Lau, E.; Mowat, F.; Halpern, M. Projections of Primary and Revision Hip and Knee Arthroplasty in the United States from 2005 to 2030. J. Bone Jt. Surg. 2007, 89, 780-785. [CrossRef]

4. Affatato, S.; Ruggiero, A.; Merola, M. Advanced biomaterials in hip joint arthroplasty. A review on polymer and ceramics composites as alternative bearings. Compos. Part B Eng. 2015, 83, 276-283. [CrossRef]

5. Rajaee, S.S.; Theriault, R.V.; Pevear, M.E.; Smith, E.L. National Trends in Primary Total Hip Arthroplasty in Extremely Young Patients: A Focus on Bearing Surface Usage From 2009 to 2012. J. Arthroplast. 2016, 31, 63-68. [CrossRef] [PubMed]

6. Affatato, S.; Bersaglia, G.; Emiliani, D.; Foltran, I.; Taddei, P.; Reggiani, M.; Ferrieri, P.; Toni, A. The performance of gamma- and EtO-sterilised UHMWPE acetabular cups tested under severe simulator conditions. Part 2: Wear particle characteristics with isolation protocols. Biomaterials 2003, 24, 4045-4055. [CrossRef]

7. Affatato, S.; Bersaglia, G.; Rocchi, M.; Taddei, P.; Fagnano, C.; Toni, A. Wear behaviour of cross-linked polyethylene assessed in vitro under severe conditions. Biomaterials 2005, 26, 3259-3267. [CrossRef] [PubMed]

8. Affatato, S.; Ruggiero, A.; Jaber, S.; Merola, M.; Bracco, P. Wear Behaviours and Oxidation Effects on Different UHMWPE Acetabular Cups Using a Hip Joint Simulator. Materials 2018, 11, 433. [CrossRef] [PubMed]

9. Grillini, L.; Affatato, S. How to measure wear following total hip arthroplasty. Hip Int. 2013, 23, $233-242$. [CrossRef] [PubMed]

10. Affatato, S.; Zavalloni, M.; Spinelli, M.; Costa, L.; Bracco, P.; Viceconti, M. Long-term in-vitro wear performance of an innovative thermo-compressed cross-linked polyethylene. Tribol. Int. 2010, 43, 22-28. [CrossRef]

11. Affatato, S.; Testoni, M.; Cacciari, G.L.; Toni, A. Mixed oxides prosthetic ceramic ball heads. Part 2: Effect of the $\mathrm{ZrO}_{2}$ fraction on the wear of ceramic on ceramic joints. Biomaterials 1999, 20, 971-975. [CrossRef]

12. Affatato, S.; Spinelli, M.; Zavalloni, M.; Mazzega-Fabbro, C.; Viceconti, M. Tribology and total hip joint replacement: Current concepts in mechanical simulation. Med. Eng. Phys. 2008, 30, 1305-1317. [CrossRef] [PubMed]

13. Dumbleton, J.H. Tribology of Natural and Artificial Joints; Elsevier: New York, NY, USA, 1981.

14. Petersen, D.; Link, R.; Wang, A.; Polineni, V.; Essner, A.; Sokol, M.; Sun, D.; Stark, C.; Dumbleton, J. The Significance of Nonlinear Motion in the Wear Screening of Orthopaedic Implant Materials. J. Test. Eval. 1997, 25, 239-245. [CrossRef]

15. Affatato, S.; Bersaglia, G.; Foltran, I.; Emiliani, D.; Traina, F.; Toni, A. The influence of implant position on the wear of alumina-on-alumina studied in a hip simulator. Wear 2004, 256, 400-405. [CrossRef]

16. Astarita, A.; Rubino, F.; Carlone, P.; Ruggiero, A.; Leone, C.; Genna, S.; Merola, M.; Squillace, A. On the Improvement of AA2024 Wear Properties through the Deposition of a Cold-Sprayed Titanium Coating. Metals 2016, 6, 185. [CrossRef]

17. Taylor, M.; Prendergast, P.J. Four decades of finite element analysis of orthopaedic devices: Where are we now and what are the opportunities? J. Biomech. 2015, 48, 767-778. [CrossRef] [PubMed]

18. Brekelmans, W.A.M.; Poort, H.W.; Slooff, T.J.J.H. A New Method to Analyse the Mechanical Behaviour of Skeletal Parts. Acta Orthop. Scand. 1972, 43, 301-317. [CrossRef] [PubMed]

19. Bergmann, G.; Graichen, F.; Rohlmann, A. Hip joint loading during walking and running, measured in two patients. J. Biomech. 1993, 26, 969-990. [CrossRef]

20. Bergmann, G.; Bergmann, G.; Deuretzabacher, G.; Deuretzabacher, G.; Heller, M.; Heller, M.; Graichen, F.; Graichen, F.; Rohlmann, A.; Rohlmann, A.; et al. Hip forces and gait patterns from rountine activities. J. Biomech. 2001, 34, 859-871. [CrossRef]

21. Bergmann, G.; Kniggendorf, H.; Graichen, F.; Rohlmann, A. Influence of shoes and heel strike on the loading of the hip joint. J. Biomech. 1995, 28, 817-827. [CrossRef]

22. Ruggiero, A.; Merola, M.; Affatato, S. On the biotribology of total knee replacement: A new roughness measurements protocol on in vivo condyles considering the dynamic loading from musculoskeletal multibody model. Meas. J. Int. Meas. Confed. 2017, 112. [CrossRef]

23. Van der Ploeg, B.; Tarala, M.; Homminga, J.; Janssen, D.; Buma, P.; Verdonschot, N. Toward a more realistic prediction of peri-prosthetic micromotions. J. Orthop. Res. 2012, 30, 1147-1154. [CrossRef] [PubMed] 
24. Damsgaard, M.; Rasmussen, J.; Christensen, S.T.; Surma, E.; de Zee, M. Analysis of musculoskeletal systems in the AnyBody Modeling System. Simul. Model. Pract. Theory 2006, 14, 1100-1111. [CrossRef]

25. Vaughan, C.; Davis, B.L.; O'Connor, J.C. The man data set from “Dynamics of Human Gait”. Hum. Kinet. Publ. 1992. Available online: https:/ /isbweb.org/data (accessed on 6 April 2018).

26. Siemienski, A. Soft saturation-An idea for load sharing between muscles. Application to the study of human locomotion. In Biolocomotion: A Century of Research Using Moving Pictures; Cappozzo, A., Marchetti, M., Tosi, V., Eds.; Promograph: Rome, Italy, 1992; pp. 293-303.

27. Barreto, S.; Folgado, J.; Fernandes, P.R.; Monteiro, J. The Influence of the Pelvic Bone on the Computational Results of the Acetabular Component of a Total Hip Prosthesis. J. Biomech. Eng. 2010, 132, 54503. [CrossRef] [PubMed]

28. Kurtz, S.M.; Villarraga, M.L.; Herr, M.P.; Bergström, J.S.; Rimnac, C.M.; Edidin, A.A. Thermomechanical behavior of virgin and highly crosslinked ultra-high molecular weight polyethylene used in total joint replacements. Biomaterials 2002, 23, 3681-3697. [CrossRef]

29. Laurian, T.; Tudor, A. Some Aspects Regarding the Influence of the Clearance on the Pressure Distribution in Total Hip Joint Prostheses. In Proceedings of the National Tribology Conference RotTrib03, Galati, Romania, 24-26 September 2003.

30. Merola, M.; Ruggiero, A.; de Mattia, J.S.; Affatato, S. On the tribological behavior of retrieved hip femoral heads affected by metallic debris. A comparative investigation by stylus and optical profilometer for a new roughness measurement protocol. Measurement 2016, 90, 365-371. [CrossRef]

31. Affatato, S.; Ruggiero, A.; Merola, M.; Logozzo, S. Does metal transfer differ on retrieved Biolox ${ }^{\circledR}$ Delta composites femoral heads? Surface investigation on three Biolox ${ }^{\circledR}$ generations from a biotribological point of view. Compos. Part B Eng. 2017, 113, 164-173. [CrossRef]

32. Ruggiero, A.; D'Amato, R.; Gómez, E. Experimental analysis of tribological behavior of UHMWPE against AISI420C and against TiAl6V4 alloy under dry and lubricated conditions. Tribol. Int. 2015, 92, 154-161. [CrossRef]

33. Ruggiero, A.; D'Amato, R.; Gómez, E.; Merola, M. Experimental comparison on tribological pairs UHMWPE/TIAL6V4 alloy, UHMWPE/AISI316L austenitic stainless and UHMWPE/ $\mathrm{AL}_{2} \mathrm{O}_{3}$ ceramic, under dry and lubricated conditions. Tribol. Int. 2016, 96, 349-360. [CrossRef]

34. Shen, F.-W.; Lu, Z.; McKellop, H.A. Wear versus Thickness and Other Features of 5-Mrad Crosslinked UHMWPE Acetabular Liners. Clin. Orthop. Relat. Res. 2011, 469, 395-404. [CrossRef] [PubMed]

35. Mattei, L.; di Puccio, F. Wear Simulation of Metal-on-Metal Hip Replacements with Frictional Contact. J. Tribol. 2013, 135, 21402. [CrossRef]

36. Matsoukas, G.; Willing, R.; Kim, I.Y. Total Hip Wear Assessment: A Comparison Between Computational and In Vitro Wear Assessment Techniques Using ISO 14242 Loading and Kinematics. J. Biomech. Eng. 2009, 131, 41011. [CrossRef] [PubMed]

37. Teoh, S.H.; Chan, W.H.; Thampuran, R. An elasto-plastic finite element model for polyethylene wear in total hip arthroplasty. J. Biomech. 2002, 35, 323-330. [CrossRef]

38. Maxian, T.A.; Brown, T.D.; Pedersen, D.R.; Callaghan, J.J. A sliding-distance-coupled finite element formulation for polyethylene wear in total hip arthroplasty. J. Biomech. 1996, 29, 687-692. [CrossRef]

39. Gao, Y.; Jin, Z.; Wang, L.; Wang, M. Finite element analysis of sliding distance and contact mechanics of hip implant under dynamic walking conditions. Proc. Inst. Mech. Eng. Part H J. Eng. Med. 2015, 229, 469-474. [CrossRef] [PubMed]

40. Bevill, S.L.; Bevill, G.R.; Penmetsa, J.R.; Petrella, A.J.; Rullkoetter, P.J. Finite element simulation of early creep and wear in total hip arthroplasty. J. Biomech. 2005, 38, 2365-2374. [CrossRef] [PubMed]

41. Maxian, T.A.; Brown, T.D.; Pedersen, D.R.; Callaghan, J.J. Adaptiive finite element modeling of long-term polyethylene wear in total hip arthroplasty. J. Orthop. Res. 1996, 14, 668-675. [CrossRef] [PubMed]

42. Di Puccio, F.; Mattei, L. Biotribology of artificial hip joints. World J. Orthop. 2015, 6, 77. [CrossRef] [PubMed]

43. Tudor, A.; Laurian, T.; Popescu, V.M. The effect of clearance and wear on the contact pressure of metal on polyethylene hip prostheses. Tribol. Int. 2013, 63, 158-168. [CrossRef]

(C) 2018 by the authors. Licensee MDPI, Basel, Switzerland. This article is an open access article distributed under the terms and conditions of the Creative Commons Attribution (CC BY) license (http://creativecommons.org/licenses/by/4.0/). 